\title{
Editorials
}

Audit:

time to review the cycle

\section{THE STATE OF AUDIT}

Medical audit's widespread implementation was first proposed in 1989 by the then Health Secretary, Kenneth Clark. He defined it as:

quality assurance in clinical work ... [that] entails a measurement of performance [that] must be a key part of continuing professional development.'

He emphasised the importance of being systematic, critical, and focusing on quality outcomes for patients. ${ }^{2}$ Audit is now ingrained within the medical profession, falling under the umbrella of 'Quality Improvement': a term describing activities which implement changes leading to better outcomes. These vary from projects conducted at personal levels to organisational ones. Arguably, however, audit does not always impact on the quality of care we provide in general practice as significantly as Clark envisaged.

A number of successful and effective audits, such as the PRACtICe study ${ }^{3}$ and the National Audit of Schizophrenia, ${ }^{4}$ are being conducted and have had their recommendations adopted nationally. Some smaller audits will have also led to improvements in care for local populations, but there are many more that will have only made a minor impact, if at all.

The importance of audit is underlined by regulatory and representative bodies: the General Medical Council (GMC) has produced guidance requiring all doctors to participate in audit and this is supported by the Royal College of General Practitioners (RCGP) within the revalidation process. Professional audit organisations, such as PRIMIS, have developed software programmes that search patient registers and identify those with diagnoses, such as atrial fibrillation, that may benefit from treatment. This enables benchmarking and comparison between practices, as well as helping to achieve Quality and Outcomes Framework targets.

The RCGP is proactive in facilitating national audit through its Clinical Innovation and Research Centre and has created toolkits to aid individual audits. It promotes the importance of audit to trainees through the Kuenssberg award for outstanding projects and encouraging presentations at its national conference.
Potentially these awards will only appeal to the brightest and best who are already motivated towards research and will fail to facilitate an inclusive approach. Within the curriculum, audit is given as an example of demonstrating competency through naturally occurring evidence'. However, it is not a mandatory requirement for award of the Certificate of Completion of Training. There is no national agreement on the use of audit within training and, subsequently, individual deaneries vary in their requirements.

\section{THE TRAINEE'S PERSPECTIVE}

Gilbert et al found that 'doctors in training have a desire and perceived ability to contribute to improvement ... but do not regard their working environment as receptive to their skills' 5 Sadly, this resonates with our experiences. The initial exposure to audit begins within hospital rotations as a mandatory requirement of Foundation training. These formative events can dictate the junior doctor's approach to audit and research for the rest of his or her career. Audits conducted during hospital posts often have little relevance to general practice training and are at the behest of the host department. The opportunity to combine a primary-secondary care project is limited at this stage, mainly due to time restrictions and lack of knowledge of lor connections with) primary care systems.

A literature review 6 identified the main barriers to good-quality audit (Box 1). Little seems to have changed in the 14 years since this article's publication.

Well-meaning but over-ambitious audit ideas and a lack of support from senior colleagues can lead to an inefficient use of time collecting data, an experience that trainees quickly learn not to repeat. An undesirable consequence of this is that trainees may preferentially select topics requiring minimal investment of time and effort to achieve audit completion and satisfy curriculum goals. In the process audit becomes a mundane, tick-box

\section{Box 1. Barriers to audit 6}

- Lack of resources ltime, dedicated staff, and inadequate financial/practical resources)

- Lack of expertise in project design and analysis

- Lack of education/training in audit methods and lack of access to skilled and proactive support staff

- Lack of clear vision for outcomes

- Organisational barriers to audit and implementation of findings: absence of a supportive working relationship between clinicians and managers

exercise. Additionally, the short duration of specialty rotations (4-6 months) limits the opportunity to complete the audit cycle. This deprives trainees of the chance to witness the impact of their hard work on practice and the personal development that this may bring

\section{THE FUTURE OF AUDIT IN GENERAL PRACTICE: A VISION}

While we acknowledge the importance of auditing individual practices, this restricts the interpretation of results to a limited population. We feel quality improvement is more effective in a broader context.

Successful examples of this are the surgical trainee-led research collaborative groups being established throughout the UK. ${ }^{7,8}$ They bring geographically separate but like-minded trainees together to audit or research a subject according to the same protocol with support and coordination from regional centres (www.asit.org/ resources/collaboratives). We propose this model of combining results could easily be replicated within general practice alongside existing training resources, raising standards and producing relevant, meaningful outcomes. Naturally occurring groups of motivated trainees (for example from VTS or locality training) could form collaboratives of peer investigators within their first year of training. This generates opportunities for management, leadership, 


\section{"This process would enhance quality and empower trainees to instigate positive change ...}

teamworking, support, and training. It can capitalise on the continuity that GP training provides and enable data collection to continue long after individuals rotate from a post. In Manchester, a thriving variant of this encourages registrars to formulate audit questions within learning sets and compare individual practices (personal communication, ADanczak, 2014). However, beginning in the first year of training allows additional time to complete the audit cycle and for lessons to be learned about the challenges of implementing institutional change and service improvement.

We believe audit conducted by general practice trainees should be relevant to primary care. If trainees were keen to perform an audit within a particular specialty rotation, it would be prudent to focus on areas where it interacts with primary care. Conflicts of interest between the audit department and trainees have been identified as a barrier to completion of audit. ${ }^{9}$ We envisage that trainees would retain autonomy in selecting topics which relate to areas of interest and identified need; the fresh-eyes on the front line are well placed for this. This process would enhance quality and empower trainees to instigate positive change and may even drive them to complete more ambitious studies than would be possible when working alone.

\section{IMPLEMENTATION}

Clinical commissioning groups represent an opportunity for audit coordination within England. Each one could form an audit committee with a strategic role in determining priorities across their region. These could be aligned with RCGP enduring clinical priorities and suggest topics for audit, provide assistance, resources, and training, extending to basic research skills and updates in critical appraisal. This supportive role could facilitate collaboration, not only between GP trainees and other doctors, but also with other healthcare professionals, enabling a multidisciplinary approach to quality improvement.

This work would expand the understanding of, and respond to, the needs of local populations, developing trainees' community orientation. It also has clear channels for the dissemination of results and recommendations relevant to individual practices, the region, and, potentially, further afield. It is likely to inspire individual trainees and show them the impact that audit can have on their patients and themselves. This could also induce positive attitudes towards primary care research.

We appreciate there is a balance to be struck between making audit effective and being too prescriptive. We would not want this proposal to inhibit innovation or stifle intellectual creativity: the last thing our curriculum needs is another tick-box. Enthusing trainees with the power of relevant, effective, collaborative projects that lead to measurable service improvements for patients can only help shape a positive view of audit that will remain with them career-long.

\section{Simon Glew,}

NIHR Academic Clinical Fellow in Primary Care, Brighton and Sussex Medical School, Brighton.

\section{Sangeetha Sornalingam,}

NIHR Academic Clinical Fellow in Primary Care, Brighton and Sussex Medical School, Brighton.

\section{Timothy Crossman,}

NIHR Academic Clinical Fellow in Primary Care, Brighton and Sussex Medical School, Brighton.

\section{Provenance}

Freely submitted; externally peer reviewed.

DOI: 10.3399/bjgp14X682573

\section{ADDRESS FOR CORRESPONDENCE}

\section{Simon Glew}

Brighton and Sussex Medical School, Room 321, Mayfield House, Village Way, Falmer BN1 9PH, UK.

E-mail: s.glewabsms.ac.uk

\section{REFERENCES}

1. Clarke K. Speech to the joint meeting of the National Association of Clinical Tutors, the Conference of Postgraduate Deans, and the National Association of Postgraduate Centre Administrators. York, 6 July 1990.

2. Department of Health. Working for patients. (white paper) London: DoH, 1989.

3. Avery T, Barber N, Ghaleb M, et al. Investigating the prevalence and causes of prescribing errors in general practice: The PRACtICe Study. London: General Medical Council, 2012.

4. Royal College of Psychiatrists. Report of the National Audit of Schizophrenia (NAS) 2012. London: Healthcare Quality Improvement Partnership, 2012.

5. Gilbert A, Hockey P, Vaithianathan R, et al. Perceptions of junior doctors in the NHS about their training: results of a regional questionnaire. BMJ Qual Saf 2012. DOI:10.1136/ bmjqs-2011-000611.

6. Johnston G, Crombie IK, Davies HT, et al. Reviewing audit: barriers and facilitating factors for effective clinical audit. Qual Health Care 2000; 9(1): 23-36.

7. Bhangu A, Kolias AG, Pinkney T, et al. Surgical research collaboratives in the UK. Lancet 2013. DOI: 10.1016/S0140-6736(13)62013-9).

8. Bartlett D, Pinkney TD, Futaba K, et al, on behal of the West Midlands Research Collaborative. Trainee led research collaboratives: pioneers in the new research landscape. BMJ careers 2012. http://careers.bmj.com/careers/advice/ view-article.html?id=20008342 laccessed 21 Oct 2014).

9. Cai A, Greenall J, Col Dau Ding D. UK Junior Doctors' Experience of Clinical Audit in the Foundation Programme. Br J Med Pract 2009; 2(3): $42-45$. 